\title{
Os médicos e a gestão do cuidado em serviços hospitalares de emergência: poder profissional ameaçado?
}

\section{Physicians and management of emergency hospitals: professional power threatened?}

\section{Los médicos y la gestión del cuidado en servicios hospitalarios de urgencia: ¿un poder profesional amenazado?}

Luiz Carlos de Oliveira Cecilio ${ }^{1}$

Tiago Correia 2

Rosemarie Andreazza 1

Arthur Chioro 1

Graça Carapinheiro ${ }^{3}$

Nelma Lourenço de Matos Cruz 1

Luciana Soares de Barros 1

doi: 10.1590/0102-31100242918

\section{Correspondência}

L. C. O. Cecilio

Rua Dr. Louis Couty 35, apto. 92, São Paulo, SP 05436-030, Brasil.

luizcecilio60@gmail.com lidade da assistência, maior rotatividade dos leitos, com consequente redução do tempo de internação e custos hospitalares. O constante e atualizado acompanhamento do paciente, compartilhado pela equipe profissional em reuniões sistemáticas é seu elemento mais marcante e inovador. O objetivo foi caracterizar os prováveis impactos da adoção de tal arranjo no poder profissional (autonomia e autoridade) dos médicos. Estudo qualitativo em hospital de urgência-emergência municipal com uso das seguintes técnicas de produção de dados: etnografia do cotidiano do hospital, com observação e registro em diários de campo, e realização de seminários compartilhados entre pesquisadores e equipes. Os médicos valorizam o trabalho multiprofissional como um qualificador de sua prática, em uma linha auxiliar e complementar. Acresce que o Kanban tende a ser controlado por "híbridos" (médicos que acumulam funções gerenciais e clínicas) que traduzem sinergias entre "gestão clínica" $e$ "gestão de leitos". Assim, interferências no trabalho dos médicos não são exercidas de fora, e as suas decisões clinicas continuam a condicionar o trabalho dos demais grupos profissionais. Os médicos não percebem sua autoridade e autonomia ameaçadas pelo Kanban, dada a articulação entre a autoridade administrativa e a autoridade profissional. Contudo, aspectos relacionados à hibridização e estratificação interna da profissão médica precisam ser mais convocados para o debate do poder profissional em saúde.

Assistência Integral à Saúde; Serviço Hospitalar de Emergência; Assistência Centrada no Paciente
1 Universidade Federal de São Paulo, São Paulo, Brasil.
2 Universidade Nova de Lisboa, Lisboa, Portugal.

3 Instituto Universitário de Lisboa, Lisboa, Portugal. 


\section{Introdução}

Os serviços hospitalares de emergência enfrentam comumente fenômenos de demanda excessiva, como a superlotação e queixas relativas à qualidade do cuidado. Daí resulta a insatisfação dos usuários, seja pelo tempo de espera para atendimento, seja pela indisponibilidade de leitos hospitalares para internações, acarretando na permanência de um grande número de pacientes por longos períodos em macas nos corredores 1,2,3,4,5.

Intervenções que buscam maior efetividade nos serviços hospitalares de emergência, baseadas em novos arranjos tecnológicos de organização do cuidado e de leitos, procuraram melhorar a capacidade de acolher, identificar riscos, ofertar cuidados em saúde e gerar saídas nos serviços hospitalares de emergência, tendo sido experimentadas em diversos países 4,6. Representam um conjunto de tecnologias que aplicadas preferencialmente de forma combinada constituem-se em modalidades de intervenção de caráter multiprofissional, destinadas a fins práticos na gestão e produção do cuidado em saúde 7,8. Algumas tecnologias são destinadas à gestão de leitos, compreendida como as práticas voltadas ao monitoramento dos motivos de permanência hospitalar, a fim de se elencar recursos necessários para alcance de sucesso terapêutico. Outras, destinam-se à gestão clínica e buscam monitorar e garantir a execução de melhores práticas terapêuticas e o alcance de resultados clínicos nos padrões estabelecidos 9,10 .

Especificamente no Brasil, o Ministério da Saúde implantou um conjunto de intervenções a partir de 2003, como o Serviço de Atendimento Móvel de Urgência (SAMU), as Unidades de Pronto Atendimento (UPA) e a Política de Qualificação da Atenção à Saúde (QUALISUS). No componente hospitalar, houve indução para uso e disseminação concomitante dos dispositivos e arranjos da Política Nacional de Humanização, como o acolhimento com classificação de risco, visando ao crescimento de oferta de leitos de retaguarda, bem como incentivo à implantação de tecnologias seletivas de caráter regulatório para uso adequado e equitativo dos recursos. Práticas substitutivas hospitalares na forma de cuidados domiciliares produzidos pelas equipes e serviços da atenção básica foram também incorporadas $11,12,13,14$.

Beltrammi 15 destaca que intervenções baseadas na mera expansão do número de leitos no serviços hospitalares de emergência não são efetivas, pois, isoladas, não impactam no tempo de permanência. De fato, hospitais que fizeram uso de intervenções dedicadas ao aperfeiçoamento dos processos e dos fluxos dos serviços hospitalares de emergência obtiveram maior efetividade para atenuar ou reduzir o problema da superlotação, quando comparados com aqueles que fizeram uso de intervenções dedicadas exclusivamente às entradas ou às saídas 5,10,16,17,18,19.

Nesse cenário, a experimentação de novos arranjos tecnológicos para o cuidado adquire importância, seja ao aperfeiçoar a capacidade de acolher e de identificar riscos das pessoas que buscam cuidados hospitalares, melhorando o modo como se dá a entrada do paciente no hospital, seja "gerando saídas” dos serviços hospitalares de emergência mais articuladas com outros pontos de atenção da rede, condição fundamental para se garantir a continuidade do cuidado.

O Kanban é um desses novos arranjos tecnológicos, um dispositivo de gestão de leitos. Sua adoção permite qualificar a coordenação do cuidado, aperfeiçoar a tomada de decisão clínica e o uso do recurso leito, tendo, portanto, íntima relação com a gestão clínica. No modo como tem sido usualmente adaptado para a atenção hospitalar, pressupõe que diariamente, após a realização das atividades assistenciais padronizadas, os profissionais de saúde se reúnam sob a liderança de um profissional da equipe que desempenha a atividade de supervisor de gestão da clínica para processamento das dimensões avaliativas dos projetos terapêuticos em andamento. Coletivamente, procuram identificar as condições de saúde de cada paciente, as necessidades atuais e futuras e a interação dinâmica entre essas e as intervenções terapêuticas propostas, com o objetivo comum de definir a prioridade vigente para o cuidado efetivo, atribuindo-se ações, recursos, responsáveis e prazos. O tempo de permanência hospitalar é a variável balizadora de todo o processo 9 .

Ao conformar o trabalho da equipe multiprofissional, o Kanban possibilita ampliar a responsabilidade dos sujeitos implicados no cuidado e produzir respostas operacionais. Sua ação tem sido potencializada pela institucionalização da horizontalidade do cuidado médico, que objetiva aprimorar a decisão clínica e a coordenação do cuidado, ao compartilhar as decisões e a coordenação do cuidado 
com outros profissionais, pelas visitas multidisciplinares, atividades rotineiras das equipes de alto desempenho. Tal associação visa produzir melhor decisão clínica, além de propor recursos necessários para o cuidado, incentivando a sinergia entre os múltiplos saberes. O uso de protocolos clínicos hospitalares, baseados em evidência científica, guiam a decisão clínica e as melhores práticas para o cuidado seguro e efetivo 9,10,13,16,18,19.

Ao definir a expectativa de alta e o projeto terapêutico para o usuário, o Kanban dispara a necessidade de mais intervenções, articulando-se diretamente com outros arranjos tecnológicos de coordenação do cuidado, como atenção domiciliar, unidades de cuidados prolongados e linhas de cuidado $12,13,20,21,22,23$. Ele ajuda a compreender a relação entre o que acontece no serviços hospitalares de emergência e o cuidado prestado na rede de saúde; de como incide sobre essa realidade a regulação do sistema, operado pelo complexo regulador, mas também por outras lógicas regulatórias. Permite, ainda, identificar os dispositivos de rede que estão (ou não) disponíveis para garantir a continuidade do cuidado pós-hospitalar, evitando o agravamento da sua condição de saúde e em reinternação desnecessária.

Pela importância que os arranjos tecnológicos de gestão de leitos têm assumido no Sistema Único de Saúde (SUS), entre os quais o Kanban, importa analisar as suas implicações nas relações de poder profissional, na medida em que parece desafiar estruturas e processos de autoridade e autonomia bem estabelecidos nas organizações hospitalares. O hospital - a par da universidade - é um dos exemplos mais expressivos da configuração da burocracia profissional. Em traços gerais, tal configuração se caracteriza por deter duas estruturas de autoridade - uma racional-legal e uma profissional - difíceis de serem articuladas entre si 24,25,26. Enquanto a primeira se constrói em torno do típico funcionamento burocrático referido por Weber 27 (p.ex.: estandardização dos processos e elevado controle administrativo), a segunda se constrói em torno do profissionalismo médico (p.ex.: estandardização das competências e baixo controle administrativo).

A questão é que o Kanban parece desafiar a estrutura de autoridade profissional dos médicos, e por conseguinte sua autonomia, ao, via autoridade administrativa, buscar alterar modelos de organização do trabalho, fluxos de informação e a própria divisão social do trabalho.

O presente artigo procura compreender os possíveis impactos da adoção do arranjo no trabalho dos médicos, muito em particular sobre o controle das suas decisões e relações com as demais profissões e com os pacientes, elementos fundamentais na sua profissão: Como os médicos vivem tais mudanças? Há impactos na sua autoridade profissional e no grau de autonomia com que exerce seu trabalho?

\section{Material e métodos}

O artigo faz uso de dados produzidos em uma investigação matriz que objetivou compreender como arranjos de gestão do cuidado em serviços hospitalares de emergência são operacionalizados pelos profissionais e vividos pelos usuários. Para tanto, realizou-se uma pesquisa de caráter qualitativo, tipo estudo de caso 28,29 .

A eleição do Kanban para as reflexões que se pretende fazer neste texto justifica-se pelo caráter marcadamente multiprofissional do arranjo, no qual, em princípio, o médico deve compartilhar com os outros profissionais, componentes essenciais de seu trabalho, em particular o diagnóstico e a decisão terapêutica.

As estratégias metodológicas escolhidas buscaram uma aproximação micropolítica aos processos de gestão e de produção de cuidado 30 . O método principal utilizado foi a etnografia, valendo-se de uma observação intensiva do arranjo tecnológico estudado, que teve início a partir da apresentação da pesquisa às equipes gerenciais e assistenciais do hospital. Os diários de campo foram elaborados pelos pesquisadores a cada ida ao hospital, em diferentes dias e horários da semana, durante quase um ano, perfazendo um total de 50 observações. Frise-se que todas as reuniões de Kanban foram observadas, não havendo critério de inclusão. Os profissionais individualmente não foram foco de observação separada. Esse material foi processado no coletivo de pesquisadores que se reuniu em seminários quinzenais. Foram ainda realizados cinco seminários compartilhados entre os pesquisadores, profissionais e gestores do hospital para apresentação e discussão dos resultados parciais da investigação. 
No Quadro 1 estão descritas as diferentes técnicas de produção de dados utilizadas para a elaboração deste artigo 30,31,32. Todos os seminários compartilhados foram gravados e posteriormente transcritos, com anuência dos envolvidos, que assinaram o Termo de Consentimento Livre Esclarecido (CEP/ Unifesp n: 0418/2017).

\section{O contexto do estudo}

A investigação foi realizada no Hospital de Urgência Emergência (HUE) de uma rede municipal de saúde. Trata-se de uma unidade hospitalar certificada como hospital de ensino, referência para o atendimento de urgência e emergência, atendendo tanto a demanda espontânea, como a referenciada pelo SAMU e pelas UPA do município. É o componente hospitalar da Rede de Urgência e Emergência na atenção ao trauma de média complexidade e aos cuidados clínicos, cirúrgicos e pediátricos de pacientes agudizados, emergências odontológicas, oftalmológicas e ortopédicas. Juntamente com outros três hospitais, compõe o complexo hospitalar universitário gerido pelo município.

Arranjos tecnológicos propostos pela Política Nacional de Atenção Hospitalar do Ministério da Saúde 33, como o acolhimento com classificação de risco (Manchester), a gestão de leito e de cuidado (Kanban), foram implantados a partir de 2011 pela alta direção do estabelecimento, que liderou e se envolveu diretamente em sua operacionalização, em parceria com seus trabalhadores, como aposta central no projeto de enfretamento da superlotação, qualificação do cuidado e integração do hospital com a rede de saúde.

\section{Quadro 1}

Descrição das técnicas de pesquisa utilizadas.

\begin{tabular}{|c|c|c|c|}
\hline Técnica utilizada & Atores envolvidos e local & Período e duração & Objetivo \\
\hline Observação participante & $\begin{array}{c}\text { - } 3 \text { pesquisadores de campo } \\
\text { - Equipe de profissionais envolvidos na } \\
\text { operacionalização do Kanban (em suas diferentes } \\
\text { modalidades): eixos - crítico, vermelho e amarelo, } \\
\text { verde, UTI e unidade de internação } \\
\text { (adulto e criança) }\end{array}$ & $\begin{array}{c}\text { Agosto/2017 a } \\
\text { Maio/2018; } \\
\text { todos os dias da semana } \\
\text { em diferentes horários; } \\
50 \text { diários de campo }\end{array}$ & $\begin{array}{c}\text { Caracterizar o funcionamento do } \\
\text { Kanban, observando as relações } \\
\text { das equipes, dos profissionais e } \\
\text { usuários e os lugares }\end{array}$ \\
\hline $\begin{array}{l}\text { Seminários compartilhados } \\
\text { A e B }\end{array}$ & $\begin{array}{c}\text { - Coordenador da pesquisa (2) } \\
\text { - Pesquisadores de campo (2) } \\
\text { - Diretor do Hospital - coordenações dos eixos: } \\
\text { verde, crítico, internação e UTI adulto e criança. } \\
\text { - Núcleo Regulação Interna } \\
\text { - Supervisões profissionais (médicos, enfermeiros, } \\
\text { fonoaudiologia, nutricionistas, fisioterapeutas, } \\
\text { assistentes sociais) } \\
\text { - profissionais assistenciais da equipe } \\
\text { multiprofissional }\end{array}$ & $\begin{array}{c}2018 ; \\
2 \text { de } 2 \text { h de duração cada } \\
\text { um }\end{array}$ & $\begin{array}{c}\text { Discutir com os atores } \\
\text { institucionais a primeira analítica } \\
\text { dos achados obtidos pelas } \\
\text { observações participantes e do } \\
\text { processamento dos diários de } \\
\text { campo nos seminários quinzenais } \\
\text { de pesquisa }\end{array}$ \\
\hline $\begin{array}{l}\text { Seminários compartilhados } \\
\text { com os médicos }\end{array}$ & $\begin{array}{c}\text { - Coordenador da pesquisa. } \\
\text { - } 2 \text { pesquisadores de campo } \\
\text { - } 15 \text { profissionais médicos: gestores, } \\
\text { coordenadores de clínica, diaristas, plantonistas } \\
\text { (adulto e criança) }\end{array}$ & $\begin{array}{c}\text { 2018; } \\
1 \text { de } 1 \mathrm{~h} 40\end{array}$ & $\begin{array}{l}\text { Discutir com os médicos as } \\
\text { evidências colocadas tanto nos } \\
\text { seminários compartilhados A e } \\
\text { B, como aqueles apontados nas } \\
\text { analíticas do material empírico }\end{array}$ \\
\hline
\end{tabular}

UTI: unidade de tratamento intensivo. 
Ainda que o Kanban tenha sido implantado no HUE estudado, com base em um modelo padrão, em diferentes setores do estabelecimento foram produzidas reconfigurações no seu modo de funcionamento. No Quadro 2, apresenta-se a descrição do Kanban com as distintas denominações adotadas pelas equipes que atuam em diferentes setores, bem como se procura caracterizar seus diversos modos de funcionamento.

\section{Quadro 2}

Descrição do dispositivo Kanban com suas denominações, lugares e modo de funcionamento.

\begin{tabular}{|c|c|c|c|c|c|}
\hline Denominação & Local & Descrição do modo de funcionamento & Periodicidade & Profissionais & $\begin{array}{l}\text { Duração } \\
\text { (minutos) }\end{array}$ \\
\hline $\begin{array}{l}\text { Kanban da } \\
\text { pediatria }\end{array}$ & $\begin{array}{c}\text { Sala da } \\
\text { pediatria }\end{array}$ & $\begin{array}{l}\text { Os profissionais sentam livremente pela sala } \\
\text { em cadeiras e mesas, não existe uma posição } \\
\text { rigorosa, a enfermagem fica ao computador } \\
\text { atualizando a planilha e conduz a reunião } \\
\text { informando a situação do paciente. Os médicos } \\
\text { entram em algum aspecto clínico e os outros } \\
\text { profissionais em alguma demanda específica }\end{array}$ & $\begin{array}{c}\text { Diário; } \\
11 \mathrm{~h}\end{array}$ & $\begin{array}{c}\text { Assistente Social Enfermeira } \\
\text { do NIR } \\
\text { Enfermeira horizontal } \\
\text { Enfermeira plantonista } \\
\text { Fonoaudióloga } \\
\text { Médico do NIR } \\
\text { Médico preceptor e } \\
\text { Médico residente } \\
\text { Médico plantonista - pediatras }\end{array}$ & 15 \\
\hline $\begin{array}{l}\text { Kanban ou } \\
\text { Round da UTI } \\
\text { pediátrica }\end{array}$ & \begin{tabular}{|c|} 
Sala \\
pequena na \\
UTI
\end{tabular} & $\begin{array}{c}\text { Os profissionais em pé ou sentados discutem } \\
\text { os casos. Todos têm voz. Quem conduz é a } \\
\text { enfermagem, que informa a situação do paciente } \\
\text { em relação aos procedimentos realizados ou não, } \\
\text { medicação e necessidades. Os médicos falam do } \\
\text { caso e trocam informações entre eles. Os outros } \\
\text { profissionais atuam quando há demanda. O } \\
\text { médico fica ao computador }\end{array}$ & $\begin{array}{l}\text { Diário; } \\
11 \text { h30 }\end{array}$ & $\begin{array}{c}\text { Assistente Social Enfermeira } \\
\text { do NIR } \\
\text { Enfermeira horizontal } \\
\text { Enfermeira plantonista } \\
\text { Fisioterapeuta } \\
\text { Fonoaudióloga } \\
\text { Médico do NIR } \\
\text { Médico preceptor e } \\
\text { Médico residente } \\
\text { Médico - pediatras } \\
\text { Nutricionista } \\
\text { Psicóloga }\end{array}$ & 30 \\
\hline $\begin{array}{l}\text { Kanban } \\
\text { multipro- } \\
\text { fissional } \\
\text { pediatria }\end{array}$ & $\begin{array}{c}\text { Brinque- } \\
\text { doteca }\end{array}$ & $\begin{array}{l}\text { Todos os profissionais da pediatria, incluindo } \\
\text { a UTI e a semi-intensiva; quem o conduz é a } \\
\text { enfermeira mediante a planilha do censo. O } \\
\text { clima entre os profissionais é bem tranquilo, } \\
\text { com momentos de descontração. Todos os } \\
\text { profissionais falam, alguns mais porque estão } \\
\text { envolvidos na demanda do paciente naquele } \\
\text { momento }\end{array}$ & $\begin{array}{l}\text { Semanal; } \\
11 \mathrm{~h}\end{array}$ & $\begin{array}{c}\text { Assistente Social Enfermeira } \\
\text { do NIR } \\
\text { Enfermeira horizontal } \\
\text { Enfermeira plantonista } \\
\text { Fisioterapeuta } \\
\text { Fonoaudióloga } \\
\text { Médico do NIR } \\
\text { Médico preceptor Médico } \\
\text { residente } \\
\text { Médico - pediatras } \\
\text { Nutricionista } \\
\text { Psicóloga }\end{array}$ & 60 \\
\hline $\begin{array}{l}\text { Kanban eixo } \\
\text { verde }\end{array}$ & $\begin{array}{l}\text { Não há } \\
\text { lugar fixo } \\
\text { (corredor, } \\
\text { salinha, } \\
\text { enfermaria } \\
\text { verde) }\end{array}$ & $\begin{array}{l}\text { Enfermeiros, médico e assistente social sempre } \\
\text { presentes. Quem conduz é a enfermagem com } \\
\text { o censo, informando a situação do paciente. A } \\
\text { assistente social é demandada para explicitar a } \\
\text { situação social, em particular em relação à alta. } \\
\text { A centralidade é a discussão do "destino do } \\
\text { paciente": processos de micro regulação e de } \\
\text { regulação. Todos falam. A decisão está com o NIR }\end{array}$ & $\begin{array}{c}3 \text { vezes ao dia; } \\
10 \mathrm{~h} ; \\
15 \mathrm{~h} ; \\
22 \mathrm{~h}\end{array}$ & $\begin{array}{l}\text { Assistente Social Enfermeira } \\
\text { do NIR } \\
\text { Enfermeira horizontal } \\
\text { Enfermeira plantonista } \\
\text { Médico do NIR } \\
\text { Médicos } \\
\text { Psicóloga }\end{array}$ & 15 \\
\hline
\end{tabular}

(continua) 
Quadro 2 (continuação)

\begin{tabular}{|c|c|c|c|c|c|}
\hline Denominação & Local & Descrição do modo de funcionamento & Periodicidade & Profissionais & $\begin{array}{c}\text { Duração } \\
\text { (minutos) }\end{array}$ \\
\hline $\begin{array}{l}\text { Kanban } \\
\text { unidade de } \\
\text { internação }\end{array}$ & $\begin{array}{l}\text { Sala de } \\
\text { estudos }\end{array}$ & $\begin{array}{l}\text { Os profissionais participam tranquilamente. } \\
\text { Quem conduz é a enfermagem, que informa } \\
\text { a situação do paciente em relação aos } \\
\text { procedimentos realizados ou não, medicação } \\
\text { e necessidades. Os médicos falam do caso } \\
\text { e trocam informações entre eles e indicam } \\
\text { a possibilidade de alta ou não. Os outros } \\
\text { profissionais atuam quando há demanda }\end{array}$ & $\begin{array}{l}\text { Diário; } \\
11 \mathrm{~h} \text { ou } \\
14 \mathrm{~h} 30\end{array}$ & $\begin{array}{c}\text { Assistente Social } \\
\text { Enfermeira do NIR } \\
\text { Enfermeira horizontal } \\
\text { Enfermeira plantonista } \\
\text { Fisioterapeuta } \\
\text { Fonoaudióloga } \\
\text { Médico do NIR } \\
\text { Médico preceptor e Médico } \\
\text { residente } \\
\text { Médicos } \\
\text { Nutricionista } \\
\text { Psicóloga }\end{array}$ & 20 \\
\hline $\begin{array}{l}\text { Kanban eixo } \\
\text { crítico (sala } \\
\text { amarela e sala } \\
\text { vermelha) }\end{array}$ & $\begin{array}{c}\text { No } \\
\text { corredor } \\
\text { de entrada }\end{array}$ & $\begin{array}{l}\text { Os profissionais em pé ou sentados atuam } \\
\text { tranquilamente. } \\
\text { Quem conduz é a enfermagem diarista, que } \\
\text { informa a situação de entrada do paciente } \\
\text { (SAMU, UPA etc.) além dos procedimentos } \\
\text { realizados ou não, medicação e necessidades. } \\
\text { Os médicos falam do caso e trocam informações } \\
\text { entre eles e indicam a possibilidade de } \\
\text { encaminhamento. Os outros profissionais atuam } \\
\text { quando há demanda, que aqui o serviço social } \\
\text { e a psicóloga se colocam mais em relação às } \\
\text { necessidades dos pacientes. } \\
\text { A centralidade é a decisão médica e a atuação do } \\
\text { NIR para a "saída do paciente com segurança", } \\
\text { para outros hospitais }\end{array}$ & $\begin{array}{c}\text { Diário } \\
11 \mathrm{~h} \\
22 \mathrm{~h}\end{array}$ & $\begin{array}{c}\text { Assistente Social } \\
\text { Enfermeira do NIR } \\
\text { Enfermeira horizontal } \\
\text { Enfermeira plantonista } \\
\text { Fisioterapeuta } \\
\text { Médico do NIR } \\
\text { Médico preceptor e Médico } \\
\text { residente } \\
\text { Médicos } \\
\text { Psicóloga }\end{array}$ & 15 \\
\hline $\begin{array}{l}\text { Round da sala } \\
\text { amarela }\end{array}$ & $\begin{array}{l}\text { Na sala } \\
\text { amarela }\end{array}$ & $\begin{array}{l}\text { Os profissionais sentados atuam tranquilamente } \\
\text { e de forma harmônica e colaborativa. } \\
\text { Quem conduz é a enfermagem diarista, junto } \\
\text { com o médico diarista que está no computador } \\
\text { e anota metas e condutas. Os dois informam } \\
\text { a situação de entrada do paciente (SAMU, UPA } \\
\text { etc.) além dos procedimentos realizados ou não, } \\
\text { medicação e outras necessidades. Os médicos } \\
\text { falam do caso e trocam informações entre eles } \\
\text { e a equipe, sempre presente com liberdade. } \\
\text { Indicam a possibilidade de encaminhamentos e } \\
\text { de novos procedimentos }\end{array}$ & $\begin{array}{c}5 \text { vezes na } \\
\text { semana; } \\
14 \text { h30 }\end{array}$ & $\begin{array}{c}\text { Enfermeira horizontal } \\
\text { Enfermeira plantonista } \\
\text { Farmacêutico } \\
\text { Fisioterapeuta } \\
\text { Fonoaudióloga } \\
\text { Médico preceptor - diarista } \\
\text { Médico residente } \\
\text { Nutricionista } \\
\text { Psicóloga }\end{array}$ & 60 \\
\hline
\end{tabular}

(continua) 


\begin{tabular}{|c|c|c|c|c|c|}
\hline Denominação & Local & Descrição do modo de funcionamento & Periodicidade & Profissionais & $\begin{array}{l}\text { Duração } \\
\text { (minutos) }\end{array}$ \\
\hline $\begin{array}{l}\text { Fast Hug - } \\
\text { Kanban da UTI } \\
\text { adulto }\end{array}$ & $\begin{array}{l}\text { Na sala do } \\
\text { conforto } \\
\text { médico da } \\
\text { UTI }\end{array}$ & \begin{tabular}{|} 
Os profissionais sentados e os médicos aos \\
computadores, de costa para o restante da \\
equipe, que sentam nas camas. Uma roda em \\
que nem todos se olham, o clima é frio. Quem \\
conduz é o enfermeiro diarista que informa o \\
estado geral do paciente, exames e alterações. \\
É uma discussão centrada no caso clínico, com \\
muito protagonismo médico e pouca participação \\
dos outros profissionais, sendo a fisioterapeuta \\
que acaba por falar um pouco mais. São usados \\
os instrumentos de metas diárias e alertas \\
clínicos por check list padronizados, \\
além do censo
\end{tabular} & $\begin{array}{c}5 \text { vezes na } \\
\text { semana; } \\
10 \mathrm{~h}\end{array}$ & $\begin{array}{c}\text { Enfermeira horizontal } \\
\text { Enfermeira plantonista } \\
\text { Farmacêutico } \\
\text { Fisioterapeuta } \\
\text { Fonoaudióloga } \\
\text { Médico - diarista e } \\
\text { plantonista } \\
\text { Nutricionista } \\
\text { Psicóloga }\end{array}$ & 70 \\
\hline
\end{tabular}

NIR: Núcleo Interno de Regulação; SAMU: Serviço de Atendimento Móvel de Urgência; UPA: Unidade de Pronto Atendimento; UTI: Unidade de Tratamento Intensivo.

Fonte: Arranjos Tecnológicos de Gestão do Cuidado em um Hospital de Pronto Socorro (FAPESP-PPSUS-CNPq 2016/15025-7) https://www.researchgate. net/publication/339080258_Arranjos_tecnologicos_de_gestao_do_cuidado_em_um_Hospital_de_Pronto_Socorro_Relatorio_tecnico-cientifico_final (acessado em 17/Ago/2018).

\section{Análise dos dados}

Como o artigo problematiza as transformações de um arranjo multiprofissional como o Kanban na autoridade e autonomia dos médicos, importa clarificar que, neste texto, autoridade e autonomia são operacionalizados como duas dimensões do conceito de poder médico. Pode-se buscar, nas Ciências Sociais e Humanas, várias concepções de poder: como a violência legitimada em Weber 34, como ação concertada em Hannah Arendt 35, como fruto da cooperação em Talcott Parsons 36, como ação sobre ação em Michel Foucault 37, ou seja, múltiplas possibilidades de definição de poder, só para dar alguns exemplos.

Cecilio 38 sugere que uma combinação eclética dessas abordagens poderá ser usada, ora enfatizando uma, ora enfatizando mais outra dessas concepções nos estudos organizacionais, a depender dos seus objetivos, e do modo como o objeto de investigação é construído. É quase inevitável que tais definições gerais e amplas devam ser descodificadas em categorias mais operacionais, capazes de funcionar como "chaves de interpretação" de determinado material empírico produzido no campo. O conceito de poder médico será utilizado numa perspectiva weberiana, como autoridade médica para o exercício do monopólio do diagnóstico e da instituição da terapêutica, submetendo a ela as demais categorias profissionais. E, o que é mais importante, seguindo com Weber, autoridade reconhecida como legítima. Por outro lado, faz-se uso da dimensão de autonomia que permite uma maior aproximação do empírico, qual seja, a decisão clínica, o traço mais marcante da autonomia médica. Assim, o "poder médico" traduz uma autoridade socialmente legitimada, aceita como tal, não de um modo geral, mas por um grupo de pessoas específico, como, por exemplo, a equipe multiprofissional de um serviço ou equipamento de saúde. E decisão clínica como um atributo decorrente de tal autoridade.

Os conteúdos dos diários de campo foram organizados em três grandes blocos: as relações internas à equipe (divisão técnica e social do trabalho, linhas de autoridade e comando, relações de cooperação e conflito), as relações das equipes com os usuários (escuta/negociação, imposição/disciplinamento) e as relações da equipe com a direção do hospital (diretrizes da direção top-down e autogovernos das equipes, reprodução/criação). Desse material, selecionaram-se cenas para uma primeira restituição 
dos achados das observações nos dois primeiros seminários compartilhados com equipes de gestão e assistenciais do hospital (seminários A e B). Após a apresentação, os participantes eram convidados a expressar suas opiniões a respeito do material. Nesse período houve continuidade das observações. Contudo, dado que nos seminários foram levantadas novas evidências relacionadas ao trabalho dos profissionais, em particular dos médicos, houve a necessidade de outros encontros, com grupos profissionais específicos, no caso, o encontro com os médicos. Esse seminário permitiu uma compreensão mais apurada das questões registradas nas observações.

Este artigo fez uso, para sua elaboração, de todas as observações referentes às práticas dos médicos e de suas falas nos seminários compartilhados. Após a leitura do extenso material empírico, a análise foi organizada em três pontos: Gestão clínica e gestão de leito: quando o poder administrativo e poder médico se abraçam; Os médicos e o Kanban: recusa, adesão ou indiferença?; "Poder médico": o monopólio da decisão clínica segue inabalado no Kanban?

\section{Resultados e discussão}

\section{Gestão clínica e gestão de leito: quando o poder administrativo e poder médico se abraçam}

Quando a então direção do hospital optou pela implantação do Kanban, foi estabelecida sua composição, modos de coordenação e funcionamento de maneira padronizada para todos os setores. Com o passar do tempo, foram verificados três fatos correlacionados, mas com certeza mutuamente reforçadores. O primeiro fato foi a enorme plasticidade dos arranjos que assumem configurações e lógicas de funcionamento muito diferentes entre si em cada unidade, sempre mediante forte autogoverno dos trabalhadores, que fazem as adaptações e ajustes de acordo com suas necessidades, perfil da clientela e dinâmica da demanda (tal como mencionado no Quadro 2). Esse fato por si só sinaliza mais uma vertente das microrregulações que se vão operando no interior das organizações de saúde, mesmo sem visibilidade para as chefias institucionais (administração) e para a regulação política externa às organizações.

Em segundo lugar, configurou-se uma grande adesão dos trabalhadores aos arranjos, que foram mantidos em funcionamento mesmo quando da mudança do gestor municipal e da equipe dirigente do hospital. O terceiro fato foi a criação do Núcleo Interno de Regulação (NIR), nos moldes do preconizado pela Política Nacional de Atenção Hospitalar 33 que, no caso do hospital estudado, conseguiu uma articulação orgânica com o Kanban. O acoplamento do Kanban com o NIR (subordinado diretamente à alta direção do hospital) resultou em uma "máquina regulatória” muito potente, com consequente maior dinamismo na utilização dos leitos.

É exatamente no cruzamento e composição dessas duas linhas de autoridade que se pode constatar com mais acuidade o que se passa com a autoridade médica nesses arranjos mais contemporâneos de gestão hospitalar.

Como diz a médica que coordenava o NIR, quando da realização da pesquisa: "O Kanban é uma ferramenta de gestão pra gestão de leitos e não envolve a parte clínica. Não envolve a interferência na conduta. (...) A gente não interfere na qualidade [da conduta] (...). Então, essa é a nossa função no NIR. A agilidade de gestão, agora não condução de caso clínico”.

Há uma clara diferenciação entre o que seria a gestão clínica (a gestão do caso, o planejamento clínico e a condução do caso clínico) no espaço mais micropolítico do cuidado, e a gestão do leito, que envolveria uma dimensão mais sistêmica, regulatória, mais “macro", e que implicaria uma nova forma de autoridade, que é a autoridade administrativa, ligada diretamente à direção do hospital, mobilizadora de outros recursos e de uma rede de contatos mais ampla que extrapola o hospital.

No hospital estudado, a lógica mais "macro" da administração consegue se capilarizar, via NIR, coordenado por uma médica (até o final da investigação), até cada uma das equipes, espaço de realização do Kanban. Ocorre ali, portanto, uma potencialização das duas estratégias de gestão, e os médicos ocupam posição estratégica em ambas. No hospital, autoridades médica e administrativa se entrelaçam, embora os profissionais reconheçam o quanto cada uma teria sua lógica própria. Aqui cabe destacar o que poderia ser denominado de "híbridos", isso é, médicos que acumulam função gerencial, regulatória, com atividades clínicas. 
Ainda, se considerarmos que o diretor do hospital é médico, que o NIR está ligado diretamente à direção e é coordenado por uma médica, que espaços cruciais como a UTI estão sob coordenação de médicos, então é possível dizer que a autoridade médica não se vê questionada pelos arranjos de gestão adotados, entre os quais o Kanban.

\section{Os médicos e o Kanban: recusa, adesão ou indiferença?}

O dispositivo estudado adquire tanta força na operacionalização do cotidiano hospitalar e modelagem dos seus processos de trabalho, que não seria exagero dizer que ele vertebra o modelo assistencial do hospital. Claro que há outros mecanismos de coordenação dos trabalhos, tanto das áreas logísticas, com seus regramentos administrativos próprios, quanto da própria assistência, porém o traço marcante do Kanban é o de formatar a interface entre equipes e usuários.

Um pressuposto inicial da investigação de que haveria estratégias de resistência aos arranjos, em particular ao Kanban, por parte dos médicos, não ficou imediatamente evidente com as observações. Inicialmente, teve-se a impressão da existência de algo como um "silêncio dos médicos" em relação ao dispositivo, quando contrastado com o posicionamento de outros grupos profissionais, claramente favoráveis, senão entusiastas, em relação à sua adoção.

No correr da investigação, e com a adoção de estratégias mais participativas de produção dos dados (os seminários compartilhados), foi sendo possível reconhecer manifestações positivas em relação ao Kanban por parte dos médicos, numa postura mais de adesão do que recusa do arranjo. Tal fato poderia ser explicado, inicialmente, pelo fato de o hospital estudado estar fortemente vinculado a um competente sistema de regulação, tanto interno ao hospital e ao Complexo Hospitalar Municipal, como em relação aos demais hospitais e serviços de saúde da rede locorregional de saúde, o que contribui para imprimir maior agilidade aos leitos e fluxos de pacientes.

Como registrou uma pesquisadora durante as observações: "Ao final, fiquei no corredor para tentar conversar com essas médicas (...) Disse, em poucas palavras, que o Kanban 'melhorou o trabalho, a organização' e que esse dispositivo 'ajuda a transferir (os pacientes)'...' (Diário de Campo/DC18).

Questionados, no seminário específico dos médicos, se haveria algum incômodo, em relação ao arranjo, um médico participante respondeu: "Pelo contrário. Justamente pra poder garantir escuta durante a visita multidisciplinar e planejamento terapêutico na UTI, estimular que o médico plantonista dê a sua opinião dos casos, a fisioterapeuta que passa de segunda a sexta e às vezes até aos finais de semana, veja o que está acontecendo com os pacientes. O nutricionista diz o que ele pode melhorar, o que ele vai aumentar ou diminuir a oferta de água, vai mudar a dieta, isso junto é uma avaliação multidisciplinar. A farmacêutica é de extrema importância, ela nos diz todas as interações medicamentosas que a gente usa, ajusta as doses (...) que o paciente está. Então isso é extremamente valioso pra nós" (Médico diarista do Pronto Socorro).

Vale a pena valorizar ainda o destaque dado por outra médica para o trabalho das assistentes sociais por ser exatamente o profissional que, de algum modo, dá respostas aos "problemas sociais", frequentemente a causa mais importante para a retenção do paciente no leito, esgotados os recursos clínicos.

"O Kanban ajuda por quê? Porque aí eu tenho a psicóloga, a assistente social, a enfermagem, o médico, todos trazem os seus pontos e aí a gente identifica onde está a dificuldade, qual a família que está questionando mais, onde a gente pode abordar esse problema. Ajuda muito, principalmente, as assistentes sociais" (Médica, coordenadora de área).

Também há registro de cenas nas quais os médicos reconhecem uma ampliação positiva do escopo do seu trabalho com o Kanban.

"[Durante um Kanban na enfermaria] Discussão de um caso de usuário em confusão mental, com sintomas de abstinência e sem família (...) Depois de ouvir o relato dos outros profissionais envolvidos no caso [a médica] diz: 'Precisamos mudar a estratégia terapêutica e ajudá-lo a melhorar a consciência. Ninguém que fica contido melhora, não podemos mantê-lo contido'. Sobre o esforço relatado pela assistente social para descobrir a família do paciente, [ela] finaliza: 'Não sei se é nosso papel, mas se o paciente está aqui temos que fazer"' (DC22).

A certa altura da investigação já era possível dizer, com bastante segurança, que não havia no corpo clínico resistência visível ao Kanban. Era o momento de serem colocadas novas questões. 
À medida que o estudo acumulava evidências empíricas, uma questão foi se impondo: haveria algum impacto do funcionamento multiprofissional do Kanban sobre a decisão clínica médica? Se sim, qual? Os médicos perderiam "autoridade" ou "poder" à proporção que os arranjos se consolidassem? Haveria uma dinâmica de "poder soma zero", isso é, quando alguém ganha, o outro perde?

De início, a resposta se apresentava de modo ambíguo: ora eram apresentados argumentos no sentido de que a equipe tinha agora muito mais poder de participar/influenciar a decisão clínica, ora parecia que, no fundo, nada havia mudado, e que o médico seguia monopolizando a decisão clínica. Vejamos algumas reflexões produzidas nos seminários compartilhados, sempre que os pesquisadores indagavam sobre a "autoridade médica” e seu poder de decisão, fazendo a pergunta: afinal, quem decide? De quem é a decisão clínica? A decisão clínica está mais compartilhada com outros profissionais?

Como exemplo da posição que dizia ter havido uma distribuição ou repartição do poder médico, um médico respondeu que esse arranjo multiprofissional não lhe causava incômodo algum, já que atualmente o médico tinha que compartilhar mais as decisões, o que lhe parecia inevitável no atual estágio de especialização e fragmentação do cuidado.

“...Acho muito difícil o médico da UTI não ouvir alguém sobre ventilação mecânica. Acho muito difícil a gente não discutir nutrição com a nutricionista, melhor alimento pra dar para a criança, é o custo do hospital, é tudo junto (...). Tem médico que tem uma dificuldade enorme de entender isso. Eu estou lá falando, calma gente, é só uma questão de geração. A geração mais antiga tem o pensamento de achar que o médico é o único que vai resolver tudo. E os mais jovens, os residentes, a visão é outra. É diferente" (Médico diarista do Pronto Socorro).

Os médicos, como os demais profissionais, reiteram o tempo todo o caráter multiprofissional do cuidado, algo como se existisse uma horizontalidade real nas relações. Apenas pequenos "lapsos linguísticos" permitem entrever algo além da formalidade do discurso, como na fala abaixo, quando a médica reconhece que é ela "quem dirige as opiniões":

"Eu dirijo as opiniões e falo, então vamos fazer isso, isso, isso e isso. Alguém quer falar mais alguma coisa? Aí, vem a psicóloga com a palavra, falando que a família está se sentindo assim, assim e assado, ou, por exemplo, paciente com os cuidados paliativos, ela diz como a família está se sentindo frente àquele caso".

No seminário compartilhado com os médicos, um jovem médico, talvez confundindo "autoridade médica" com "postura autoritária do médico", fez a seguinte observação, alertando os pesquisadores de que essa seria uma "falsa questão", já que hoje, para os jovens médicos, seria natural trabalhar com equipe e compartilhando as decisões:

“...Agora uma coisa que eu acho estranho é vocês ficarem perguntando o tempo inteiro sobre a visão autoritária do médico (...) Isso eu acho que é uma visão de quem se formou há mais de vinte e cinco anos".

Por outro lado, também é possível reconhecer preocupações de alguns médicos sobre possíveis futuros impactos em suas autonomias com a manutenção e aperfeiçoamento do arranjo, o que se traduz nessa reflexão de uma médica, ela própria um bom exemplo da ambiguidade em relação às mudanças decorrentes do Kanban:

"Eu acho que o grande termômetro [das preocupações] dos médicos em relação [à perda de sua autonomia] é: até que ponto essas equipes interdisciplinares estão invadindo o meu quadrado? E isso, em alguns setores, em algumas ocasiões, invade sim e eu acho que isso não pode acontecer. Por exemplo, o NIR (Núcleo Interno de Regulação) definir o paciente que vai pra UTI ou não. Isso é uma decisão médica, isso é uma discussão ética (...). Legalmente, o médico responde pelo paciente e ponto final...". Ou ainda, quando afirma: "Se a gente tirar o médico do contexto, como a gente vai fazer? Não faz. Até que se mude o modelo, um dia, eu espero que não, eu gosto muito da importância da profissão, quem define é o médico".

Com o método etnográfico, muitas vezes é possível identificar coisas que não se captam simplesmente no discurso dos sujeitos, mas que podem ser percebidas pelo olhar atento do pesquisador, como na cena a seguir:

"O 'fast hug' [denominação utilizada no serviço para o formato do Kanban na UTI] iniciou com o médico diarista, a médica plantonista, a fisioterapeuta, a fonoaudióloga, a enfermeira. Depois chegou a farmacêutica e o nutricionista (...) Era como se tivéssemos todos em uma roda, o médico diarista e a plantonista olhavam para fora da roda enquanto os outros profissionais olhavam para o centro da roda. O clima da visita estava mais leve, havia uma interação grande entre os médicos. Quem ditou o ritmo da visita foi o diarista, ele foi falando nome do paciente, condições gerais, seguindo o roteiro de visita multi e sobre as novas condutas a 
serem adotadas. A cada alteração elou nova conduta ele dirigia o olhar para a plantonista que correspondia ao olhar confirmando a cumplicidade na conduta adotada" (DC28).

A questão do exercício de autoridade dos médicos não levar a reações explícitas desses profissionais, poderia ser visto como um indicativo de que eles não se sentem, de fato, ameaçados. Contudo, tal como se procurou salientar, silêncios e olhares podem querer dizer muitas coisas, pelo que é necessário explorar o material empírico sob os múltiplos olhares dos diferentes participantes.

\section{Conclusões}

Como conclusões poderia ser dito que: (1) há uma adesão do corpo clínico ao arranjo estudado, não lhe opondo oposição importante, tanto no plano discursivo como prático; (2) respaldados especialmente pelo poder discricionário que lhes garante o monopólio das prescrições farmacológicas e a emissão do atestado de óbito, por exemplo, os médicos do estudo não reconhecem como problema ou não se queixam do que poderia ser uma perda de sua autoridade profissional nesses arranjos (pelo contrário, valorizam o trabalho multiprofissional como um importante qualificador de sua prática, em uma linha auxiliar e complementar, que não lhes parece ameaçar sua autonomia profissional), pois o núcleo duro da decisão clínica ainda é do médico; (3) o fato de novas instâncias de regulação criadas no hospital (p.ex.: NIR) serem ocupadas por médicos leva as interferências em decisões clínicas a não serem lidas como quebra da autoridade discricionária da medicina. Em vez disso, é demonstrativo da crescente reestratificação interna à profissão médica, que vem sendo descrita na literatura internacional como consequência de abordagens gerencialistas às organizações de saúde 39,40. É também demonstrativa do processo de hibridização da profissão médica, na medida em que órgãos de regulação de processos administrativos e clínicos são ocupados por médicos 41,42. Assim, como vem sendo referido noutros países, os resultados empíricos aqui reunidos sugerem que a reestratificação e hibridização da profissão médica, percebidos enquanto dinâmicas complementares, resultam no reforço da autoridade profissional e na continuidade da autonomia clínica.

A autoridade médica incide sobre processos administrativos e clínicos, enquanto a autonomia clínica diz respeito à capacidade de bloquear intromissões vindas de fora da profissão. Uma vez mais, se é verdade que os novos arranjos tecnológicos expuseram mais o trabalho médico a olhares externos, as únicas formas efetivas de afetação do trabalho clínico identificadas ocorreram por intermédio de profissionais "híbridos", e não por outros grupos profissionais.

Mais importante do que um eventual compartilhamento, transferência ou abdicação da decisão clínica para outras profissões em arranjos multiprofissionais como o Kanban, são as novas relações que os médicos vão construindo com a lógica administrativa do hospital, fruto da irreversível institucionalização de suas práticas, o que resulta, entre outras coisas, em ter que submeter a "condução do caso" (clínica) à lógica da "gestão de leito", que, subordinada a razões de ordem administrativa, mais "sistêmicas", muitas vezes invisíveis para o médico que faz diretamente a assistência, é comandada por regramentos e decisões que, pura e simplesmente, extrapolam a decisão clínica. Portanto, o "poder médico" não pode mais ser posto de modo abstrato ou fora dos contextos nos quais a profissão é exercida hoje. Os resultados empíricos sugerem, por isso, que as estruturas de autoridade racional -legal e profissional encontradas nas organizações hospitalares não devem ser perspectivadas como contrárias, mas antes como articuláveis nas práticas profissionais 40,43,44.

Tal subordinação, em geral, não é vista como problemática pelos médicos acessados na investigação, por razões em parte já apontadas antes: uma boa dinâmica da ocupação dos leitos, com altas hospitalares facilitadas por competentes processos de regulação, o que resultaria em melhores condições para o exercício da medicina na sua dimensão técnica.

A bem-sucedida articulação entre autoridade administrativa e autoridade técnica/médica, configurada na "máquina Kanban-NIR", resultou na redução drástica da sempre problemática distância entre a direção do hospital e as dinâmicas das equipes assistenciais, em particular dos médicos, para conduzir bem seus casos. E pode ser vista como a razão principal do sucesso do Kanban e a adesão dos trabalhadores, incluindo aí os médicos.

Poderia ser dito que estamos diante de uma autonomia e uma autoridade médica não mais como valor absoluto, posto de maneira a-histórica e descontextualizada, mas entendida em novas bases, 
em novas composições, em particular na sua articulação com o poder administrativo. Artigos que exploram a dinâmica das outras profissões, ainda em elaboração, poderão compor um quadro mais completo das transformações das relações interprofissionais no hospital em estudo.

\section{Colaboradores}

L. C. O. Cecílio e T. Correia contribuíram na concepção e redação do artigo, análise, interpretação dos dados e aprovação da versão final do manuscrito. R. Andreazza, A. Chioro e G. Carapinheiro contribuíran na análise, interpretação dos dados e revisão crítica do conteúdo. N. L. M. Cruz e L. S. Barros contribuíram na análise e interpretação dos dados. Todos os autores aprovaram a versão final para publicação.

\section{Informações adicionais}

ORCID: Luiz Carlos de Oliveira Cecilio (00000002-9207-4781); Tiago Correia (0000-0001-60153314); Rosemarie Andreazza (0000-0002-33322183); Arthur Chioro (0000-0001-7184-2342); Graça Carapinheiro (0000-0003-4374-5021); Nelma Lourenço de Matos Cruz (0000-0003-04519822); Luciana Soares de Barros (0000-0001-63204308).

\section{Agradecimentos}

Agradecemos às equipes de saúde do HUE, e à Fapesp/CNPq/PPSUS - 2016 pelo apoio financeiro.

\section{Referências}

1. Deslandes SF. Frágeis deuses: profissionais de emergência entre os danos da violência e a recriação da vida. Rio de Janeiro: Editora Fiocruz; 2002.

2. Magid DJ, Asplin BR, Wears RL. The quality gap: searching for the consequences of emergency department crowding. Ann Emerg Med 2004; 44:586-8

3. Weiss SJ, Derlet R, Arndahl J, Ernst AA, Richards J, Fernández-Frackelton $\mathrm{M}$, et al. Estimating the degree of emergency department overcrowding in academic medical centers: results of the National ED Overcrowding Study (NEDOCS). Acad Emerg Med 2004; 11:38-50.

4. Giglio-Jacquemot A. Urgências e emergências em saúde: perspectivas de profissionais e usuários. Rio de Janeiro: Editora Fiocruz; 2005.

5. Bittencourt RJ, Hortale VA. Intervenções para solucionar a superlotação nos serviços de emergência hospitalar: uma revisão sistemática. Cad Saúde Pública 2009; 25:1439-54.

6. Hartz ZMA, Contandriopoulos AP. Integralidade da atenção e integração de serviços de saúde: desafios para avaliar a implantação de um "sistema sem muros". Cad Saúde Pública 2004; 20 Suppl 2:S331-6.

7. Fleury ACC. Organização do trabalho industrial: um confronto entre teoria e realidade [Tese de Doutorado]. São Paulo: Escola Politécnica, Universidade de São Paulo; 1978.

8. Ramanantso AB. Strategic technology management. Chichester: John Wiley \& Sons; 1992.

9. Beltrammi DGM, Camargo VM. Práticas e saberes no hospital contemporâneo: o novo normal. São Paulo: Editora Hucitec; 2017.

10. Cecilio LCO, Coutinho AAP, Hamze FL, Silva AF, Batista LA, Carvalho APH. Programa SOS emergências: uma alternativa de gestão e gerência para as grandes emergências do Sistema Único de Saúde. Divulg Saúde Debate 2014; (52):202-16.

11. Ministério da Saúde. Portaria no 4.279 , de 30 de dezembro de 2010. Estabelece diretrizes para a organização da Rede de Atenção à Saúde no âmbito do sistema único de saúde. Diário Oficial da União 2020; 31 dez.

12. Ministério da Saúde. Portaria no 1.600, de 7 de julho de 2011. Reformula a Política Nacional de Atenção às Urgências e institui a Rede de Atenção às Urgências no SUS. Diário Oficial da União 2011; 8 jul.

13. Ministério da Saúde. Portaria no 2.395, de 11 de outubro de 2011. Organiza o Componente Hospitalar da Rede de Atenção às Urgências no âmbito do Sistema Único de Saúde (SUS). Diário Oficial da União 2011; 13 out. 
14. Ministério da Saúde. Portaria no 1.663, de 6 de agosto de 2012. Dispõe sobre o Programa SOS Urgências e Emergências (RUE). Diário Oficial da União 2012; 7 ago.

15. Beltrammi DGM. Efetividade das intervenções para redução da superlotação nos serviços de emergência hospitalar [Dissertação de Mestrado]. São Paulo: Instituto Sírio-Libanês de Ensino e Pesquisa; 2015.

16. Bradley VM. Placing Emergency Department crowding on the decision agenda. J Emerg Nurs 2005; 31:247-58.

17. Sinreich D, Marmor Y. Ways to reduce patient turnaround time and improve service quality in emergency department. J Health Organ Manag 2005; 19:88-105.

18. Crane J, Noon C. The definitive guide to emergency department operational improvement. Boca Raton: CRC Press; 2011.

19. Grabois V, Bittencourt R. Superlotação dos serviços de emergência. In: Sousa P, Mendes W, organizadores. Segurança do paciente: conhecendo os riscos nas organizações de saúde. Rio de Janeiro: Editora Fiocruz; 2014. p. 294314.

20. Scarazzatti GL. Tendências da avaliação em saúde. Debates GV Saúde 2006; 2:22-3.

21. Campos GWS, Amaral MA. A clínica ampliada e compartilhada, a gestão democrática e redes de atenção como referenciais teórico-operacionais para a reforma do hospital. Ciênc Saúde Colet 2007; 12:849-60.

22. Bandurchin A, McNally MJ, Ferguson-Paré M. Bringing back the house call: how an emergency mobile nursing service is reducing avoidable emergency department visit for residents in long-term care homes. Nurs Leadersh 2011; 24:59-71.

23. Wang M, Wild S, Hilfiker G, Chmiel C, Sidler $\mathrm{P}$, Eichler $\mathrm{K}$, et al. Hospital-integrated general practice: a promising way to manage walk-in patients in emergency departments. J Eval Clin Pract 2014; 20:20-6.

24. Goss MNE. Patterns of bureaucracy among hospital staff physicians. In: Freidson E, editor. The hospital in modern society. New York: Free Press; 1963. p. 170-94.

25. Carapinheiro G. Saberes e poderes no hospital. Uma sociologia dos serviços hospitalares. 4a Ed. Porto: Afrontamento; 2005.

26. Correia T. Medicina: o agir numa saúde em mudança. Lisboa: Mundos Sociais; 2012.

27. Weber M. Ensaios de sociologia. Rio de Janeiro: Jorge Zahar Editor; 1982.

28. Albarello L, Digneffes F, Hiernaux J-P, Maroy C, Ruquay D, Saint-Georges P. Práticas e métodos de investigação em ciências sociais. Lisboa: Gradiva; 2000

29. Mercado F, Gastaldo D, Calderon C. Paradigmas y diseños de la investigación cualitativa en salud. Guadalajara: Universidad de Guadalajara, Coordinácion Editorial; 2002.

30. Lapassade G. As microssociologias. Brasília: Liber Livro; 2005.
31. Melucci A. Por uma sociologia reflexiva: pesquisa qualitativa e cultura. Petrópolis: Editora Vozes; 2003.

32. Poupart J, Deslauries JP, Groulx AL, Mayer R, Pires A. A pesquisa qualitativa: enfoques epistemológicos e metodológicos. Petrópolis: Editora Vozes; 2016.

33. Ministério da Saúde. Portaria no 3.390, de 30 de dezembro de 2013. Institui a Politica Nacional de Atenção Hospitalar. Secretaria de Atenção à Saúde do Brasil. Diário Oficial da União 2013; 31 dez.

34. Weber M. Economia e sociedade: fundamentos da sociologia compreensiva. Brasília: Editora Universidade de Brasília; 1991

35. Habermas J. O conceito de poder de Hannah Arendt. In: Freitag B, Rouanet SP, organizadores. Habermas - Sociologia. São Paulo: Ática; 1993. p. 109-11. (Coleção Grandes Cientistas Sociais, 15).

36. Fernández CS. Teoría, sociedad y poder en Talcott Parsons, C. Wright Mills, Jurgen Habermas y Anthony Giddens. http://bibliote cadigital.uca.edu.ar/repositorio/tesis/teoriasociedad-poder-talcott.pdf (acessado em 05/ Dez/2018).

37. Machado R. Por uma genealogia do poder [Introdução]. In: Focault M. Microfísica do poder. 22a. Ed. Rio de Janeiro: Graal; 1979. p. vii-xxiii.

38. Cecilio LCO. A micropolítica do hospital: um itinerário ético-político de intervenções e estudo [Tese de Livre-Docência]. São Paulo: Universidade Federal de São Paulo; 2007.

39. Freidson E. The changing nature of professional control. Annu Rev Sociol 1984; 10: 1-20.

40. Correia T, Denis JL. Hybrid management, organizational configuration, and medical professionalism: evidence from the establishment of a clinical directorate in Portugal. BMC Health Serv Res 2016; 16:78-109.

41. Spehar I, Frich JC, Kjekshus LE. Clinicians' experiences of becoming a clinical manager: a qualitative study. BMC Health Serv Res 2012; 12:421.

42. Kirkpatrick I, Hartly K, Kuhlmann E, Veronesi G. Clinical management and professionalism. In: Kuhlmann E, Blank RH, Bourgeault IL, Wendt C, editors. The Palgrave International Handbook of healthcare policy and governance. Hampshire: Palgrave Macmillan; 2015 p. $325-40$.

43. Dent M, Kirkpatrick I, Neogy I. Medical leadership \& management reforms in hospitals. In: Teelken C, Ferlie E, Dent M, editors. Leadership in the public sector. London: Routledge; 2012 p. 104-25.

44. Kuhlmann E, Burau V, Correia T, Lewandowski R, Lionis C, Noordegraaf M, et al. A manager in the minds of doctors: a comparison of new modes of control in European hospitals. BMC Health Serv Res 2013; 13:246. 


\section{Abstract}

Kanban is a technical arrangement for the organization of hospital care focused on the management of beds and clinical care, aimed at the quality and comprehensiveness of care and greater hospital bed turnover, and thus a reduction in length-ofstay and hospital costs. The system's most striking and innovative feature is constant, updated patient follow-up, shared by the professional team in systematic meetings. Characterize the probable impacts from the arrangement's adoption on physicians' professional power (autonomy and authority). Qualitative study in a municipal urgency-emergency hospital using the following data production techniques: ethnography of the hospital's routine, with observation and records in field diaries, and shared seminars with researchers and teams. Physicians value multi-professional work for qualifying their practice, as an ancillary and complementary line. Kanban tends to be controlled by "hybrids" (physicians who accumulate management and clinical functions) that express synergies between "clinical management" and "hospital bed management". Thus, in this arrangement interferences in physicians' work are not exercised from outside, and physicians' clinical decisions still condition the work of the other professional groups. Physicians do not see their authority and autonomy threatened by Kanban, given the linkage between management authority and professional authority. Still, aspects related to hybridization and internal stratification of the medical profession need to be better addressed in the debate on health professionals' power.

Comprehensive Health Care; Hospital Emergency Service; Patient-Centered Care

\section{Resumen}

El Kanban es una solución tecnológica para la organización del cuidado hospitalario, orientada a la gestión de camas y apartado clínico, que tiene como meta la calidad e integralidad de la asistencia, una mayor rotatividad de las camas, con la consecuente reducción del tiempo de internamiento y costes hospitalarios. El seguimiento constante y actualizado del paciente, compartido por un equipo profesional en reuniones sistemáticas, es su característica más destacable e innovadora. Caracterizar los probables impactos en la adopción de tal solución tecnológica, respecto al poder profesional (autonomía y autoridad) de los médicos. Estudio cualitativo en un hospital de urgencias municipal, mediante el uso de las siguientes técnicas de producción de datos: etnografía del día a día del hospital, con observación y registro en diarios de campo, así como la realización de seminarios compartidos entre investigadores y equipos. Los médicos valoran el trabajo multiprofesional como un elemento que cualifica en su práctica, dentro de una línea auxiliar y complementaria. Añade que el Kanban tiende a estar controlado por "híbridos" (médicos que acumulan funciones de gerencia y clínicas) que se traducen en sinergias entre "gestión clínica" y "gestión de camas". De esta forma, las interferencias en el trabajo de los médicos no se ejercen a partir de fuera y sus decisiones clinicas continúan condicionando el trabajo de los demás grupos profesionales. Los médicos no perciben que su autoridad y autonomía estén amenazadas por el Kanban, dada la coordinación entre la autoridad administrativa y la autoridad profesional. No obstante, los aspectos relacionados con la hibridización y estratificación interna de la profesión médica necesitan ser estudiados más para los debates sobre el poder profesional en salud.

Atención Integral de Salud; Servicio Hospitalar en Hospital; Atención Dirigida al Paciente
Recebido em 17/Dez/2018

Versão final reapresentada em 29/Ago/2019 Aprovado em 03/Set/2019 